高クヌッセン数流れへの適用を通した 感圧塗料の測定原理についての一考察*

\author{
山口浩 樹*1, 松 田佑*1 \\ 森 英 男 $* 2$, 新 美 智 秀*3

\section{Discussion on Mechanism of Pressure-Sensitive Paint through Application to High Knudsen Number Regime} \\ Hiroki YAMAGUCHI*4, Yu MATSUDA, \\ Hideo MORI and Tomohide NIIMI \\ *4 Department of Micro-Nano Systems Engineering, Nagoya University, \\ Furo-cho, Chikusa-ku, Nagoya-shi, Aichi, 464-8603 Japan

\begin{abstract}
The pressure-sensitive paint (PSP) is very useful and easy way to obtain the pressure distribution on surfaces. Usually the pressure distribution by the paint shows good agreement with that obtained by other methods, like a pressure tap. Here, in this study, we discuss on the property that the paint really shows, especially in high Knudsen number regime. In this regime, it is well known that a pressure tap shows good agreement with surface pressure, and not gas pressure. Therefore, a PSP experimental result is examined with a DSMC numerical result, and shows good agreement with surface pressure. To argue against the suggestion that "PSP measures pressure, not density" [Bell, J. H. et al., Annu. Rev. Fluid Mech., 33 (2001), 155-206.], a temperature sensitivity is investigated in detail. From these arguments, it is suggested that the PSP measures a number flux toward a surface.
\end{abstract}

Key Words: Pressure-Sensitive Paint, High Knudsen Number Flow, Surface Pressure, Number Flux

\section{はじめに}

感圧塗料 (Pressure-Sensitive Paint: PSP) は表面上圧 力二次元分布を容易に可視化できる手法として広く利 用されている. 高い空間分解能，時間応答性により非 定常測定にも適しており，プローブを用いない非接触 計測であるため, その応用範囲は非常に広い.

PSP による圧力計測法では，固体表面に塗布された PSP 内に存在する発光分子が酸素分子との相互作用に よって消光される原理を利用している.この測定原理 に関し，消光現象そのものについての詳細な議論は広 く行なわれており ${ }^{(1)}$, 圧力と PSP 膜内で消光に寄与す る酸素分子数の関係に関してはヘンリーの法則に依存 すると解釈されている．実験的にはPSP の示す圧力分 布は圧力タップなどの結果と非常に良く一致すること が知られているため ${ }^{(1)}$, 特に問題なく, PSP は気体の 静圧を示していると考えられている.

近年では広範囲の流れ場に対し PSP の利用が進め られるようになってきた ${ }^{(2) \sim(6)}$. たとえば, 半導体製

\footnotetext{
* 原稿受付 2008 年. 8 月 1 日.

*1 正員, 名古屋大学大学院工学研究科 (拜) 464-8603 名古幄市 干種区不老町)

*2 正員, 九州大学大学院工学研究院(业819-0395 福岡市西区 元岡 744).

*3 正員, フェロー, 名古屋大学大学院工学研究科,

E-mail : hiroki@nagoya-u.jp
}

造過程や航空宇宙分野のような気体分子の平均自由 行程が大きい系，あるいは MEMS/NEMS(Micro/Nano Electro-Mechanical Systems) といった代表長さが小さ い系などがすでに研究対象となっている．このような 流れ場においては，系の代表長さ $L$ に対する気体分子 の平均自由行程 $\lambda$ の比であるクヌッセン数 $(\mathrm{Kn}=\lambda / L)$ が大きい高クヌッセン数流れとなり, 連続体の仮定が 成立しない，その結果, 分子の運動として流れを捉え る必要があり, PSPが計測している物理量が気体の静 圧であるかどうかが重要な問題となる可能性は否定で きない．また，分子の運動という観点から PSP の測定 原理を考察することにより, PSPが本来計測している 物理量を明らかにすることができると考えられる.

そこで本研究では, 特に高クヌッセン数に適用する 場合に着目して考察を行なった．まず，既報 (7)に従い， 高クヌッセン数流れにおける圧力測定に関する既知の 問題を示し，具体的に実験結果と比較することにより 検証した. その結果を利用して PSPが測定している物 理量について分子の運動の観点からさらに考察した. なお，PSP は高分子ポリマー中に発光色素を分散させ た一般的なものを対象とし，PSP が測定しているのは 境界層内であるという仮定の下, 流れは静止状態を想 定している. 


\section{PSP 膜内への酸素分子の浸透}

PSP は発光色素がバインダーと呼ばれる高分子内に 保持される構造をとっている. そして, 膜内に浸透し た酸素分子が, 膜内を拡散する過程で励起した発光分 子を消光する. 膜に浸透する酸素分子量は平衡状態で ある場合、ヘンリーの法則を用いて説明される。ヘン リーの法則とは，気体の溶解度が小さい場合，一定の 温度で一定量の液体に溶解する気体のモル分率 $\chi$ はそ の分圧 $\pi$ に比例する，というものである.

$$
\pi=H \chi
$$

但し， $H$ は比例定数を表わし,ヘンリ一定数と呼ばれ る. PSP の場合, 酸素分子の膜への溶解度は通常小さ いので, このヘンリーの法則が成立すると考えられて いる. なお，ヘンリーの法則は温度一定の条件下で成

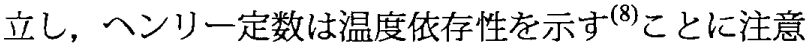
が必要である。

\section{2. 高クヌッセン数流れにおける圧力測定の問題点}

PSP を高クヌッセン数流れに適用して圧力測定を実 施することを考える. 高クヌッセン数流れにおいては, 分子の平均自由行程 $\lambda$ が系の代表長さ $L$ に比べて無 視できなくなってくる．この場合，物体表面に設置さ れた圧力孔によって測定される圧力は表面近傍におけ る状態方程式に基づく気体の圧力（以降，気体圧力） $p$ ではなく, 表面に入射する気体分子が衝突によって 与えた力積（以降, 表面圧力） $F_{n}$ に基づいて算出する 必要があることが既に知られて㧈り ${ }^{(9)}$, 極超音速希薄 流において圧力孔による実験結果と数値解析結果とを 比較した場合, 気体圧力ではなく表面圧力と良い一致 を示すことが報告されている.

この理由については, 分子運動論より状態方程式に 基づく気体圧力 $p$ と気体分子の表面に与える力積に基 づく表面圧力 $F_{n}$ を求めることによって説明できる.

気体圧力 $p$ は状態方程式より

$$
p=n k T
$$

と求められる．但し， $n$ は数密度， $k$ はボルツマン定 数, $T$ は温度である.

一方, 気体分子が表面に与える力積 $F_{n}$ は気体分子 の入射と散乱における運動量流束の变化量を考えれば 良い(7)。まず，入射してくる運動量流束は

$$
F_{z}=\frac{1}{2} n k T
$$

と求められ，散乱する運動量流束は， $z$ 方向の向きが 反対になることに注意すると

$$
F_{z}^{\prime}=-\frac{1}{2} n k T
$$

となる．ここで注意しなければならないのは，分子群 が従う温度 $T$ である．入射する分子群が従う温度は気 体の温度 $T_{g}$ であり, 一方, 表面から散乱する分子群 が従うのは固体表面に完全適応すると考えれば表面温 度 $T_{s}$ である. よって, 表面に与えられる力積, つまり 表面圧力 $F_{n}$ は

$$
F_{n}=F_{z}-F_{z}^{\prime}=\frac{1}{2} n k T_{g}+\frac{1}{2} n k T_{s}=n k \frac{T_{g}+T_{s}}{2}
$$

と求められる.

平均自由行程 $\lambda$ が小さく連続体の仮定が成立する 場合には, 表面近傍の気体温度と表面温度は等しくな る. この場合, $T_{g}=T_{s}$ より

$$
F_{n}=n k \frac{T_{g}+T_{g}}{2}=n k T_{g}=p
$$

となり, 表面圧力と気体圧力が等しくなることが分か る. 一方, 高クヌッセン数流れではこれらの温度が異 なり，この現象は温度飛躍として知られている．その 結果 $T_{g} \neq T_{s}$ となるため

$$
F_{n}=n k \frac{T_{g}+T_{s}}{2} \neq n k T_{g}=p
$$

の関係より, $F_{n} \neq p$ となる. よって, 高クヌッセン数 流れにおいては気体圧力と表面圧力が一般に異なった ものとなる.

温度飛躍は, 適応係数 $\alpha$, 比熱比 $\gamma$, 平均自由行程 $\lambda$, プラントル数 Pr を用いて, 表面法線方向 $n$ に対 して

$$
\left.T_{g}\right|_{0}-T_{s}=\left.\frac{2-\alpha}{\alpha} \frac{2 \gamma}{\gamma+1} \frac{\lambda}{\operatorname{Pr}} \frac{\partial T}{\partial n}\right|_{0}
$$

と表わすことができる ${ }^{(10)}$. 温度飛躍は気体分子の平均 自由行程と比例しており，一般に温度飛䠰は $\mathrm{Kn}>0.01$ 程度において現われることが知られている(11) ため, $\mathrm{Kn}>0.01$ 程度の高クヌッセン数流れになると気体压 力と表面圧力のずれが重要となってくることが分かる.

\section{3. 高クヌッセン数流れへの PSP の適用}

前節の議論に従うと，一般に PSP は圧力孔による測 定と良く一致することが知られているため, 高クヌッ セン数流れでは気体圧力ではなく表面圧力を示すと考 えられる.しかしその一方で, 前述の通り PSP 膜内 に浸透する酸素分子がヘンリーの法則に従うと考える と, 原理的には気体圧力に従った結果を示すことも考 えられる，そこで，実際にPSPを高クヌッセン数流れ に適用した場合において実験結果及び数值解析結果を 比較し，表面圧力と気体圧力のどちらに従うかを検証 する。 
感圧塗料を低密度気体流やマイクロ流に適用した希 少な例である文献 ${ }^{(12)}$ に示されたマイクロ円錐体周り の超音速流を解析対象とした. 先端が半頂角 $15^{\circ}$ と なっている直径 $2 \mathrm{~mm}$ のマイクロ円錐体を, マッハ数 1.89 , 全圧 $p_{0}=100 \mathrm{kPa}$, 全温 $T_{0}=293.15 \mathrm{~K}$ の一様流 中に置いた系であり, 円錐体表面に狳布した PSP に よる圧力分布が CFD 解析結果と比較検証されている (12). 上記の条件における平均自由行程は $0.2 \mu \mathrm{m}$ 程度 であるため, マイクロ円錐体の直径を系の代表長さと すると, $K n=0.0001$ である. そのため, 高クヌッセ ン数流れとは呼べないが, 円錐体の形状により先端部 では直径が小さくなること, 超音速流れであるため下 流の影響が小さいことなどから, 先端部近傍では高ク ヌッセン数流れが実現されていると考えることができ る. マイクロ円錐体表面上の圧力分布を図 1 に, 文献 ${ }^{(12)}$ に示された結果を PSP を適用した実験による結果 $p(\mathrm{PSP}), \mathrm{CFD}$ による結果 $p(\mathrm{CFD})$ として示す．CFD 解析結果は, 実験結果と比べて軸部分においては概ね 良好な一致を示すものの, マイクロ円錐体先端部にお いて圧力が徐々に立ち上がり $x<200 \mu \mathrm{m}$ で鋭く立ち上 がる傾向を捉えることができていない．この流れ場に おいてはマイクロ円錐体の半径が系の代表長さと考え られるため, マイクロ円錐体の先端に向かってクヌッ セン数が大きくなっているとみなすことができ，マイ クロ円錐体先端部での実験結果と CFD 解析結果の相 違はクヌッセン数が大きくなったためと考えることが できる.

そこで, 高クヌッセン数流れに広く用いられている 直接シミュレーションモンテカルロ (DSMC) 法により 解析を行なった．流れ場は軸対称二次元を仮定し解析 を実施した．流入条件は実験と揃え，軸外縁境界では 平衡条件，下流境界では完全流出条件，物体表面での 散乱は拡散反射とした．物体表面近傍において境界条 件の影響が現われていないことを密度分布などより確 認した. なお，実験においてマイクロ円錐体先端部お よそ $10 \mu \mathrm{m}$ 程度の領域は完全な形状となっていないも のの先端は鋭利な形状であるため，ここでは完全な円 錐体として扱った。

DSMC 法による気体圧力 $p$ (DSMC) 及び表面圧力 $F_{n}(\mathrm{DSMC})$ も含めてマイクロ円錐体表面上の圧力分布 を図 1 に示す．この図より, 気体圧力 $p$ はCFD, DSMC 法ともにマイクロ円錐体先端部における立ち上がりを 捉えることができず，一方で DSMC 法による表面圧 力 $F_{n}$ が PSP の実験結果に見られる立ち上がりを再現 できていることが分かる．若干のずれは先端部の丸ま りや軸対称境界条件の設定などの影響であると考えら

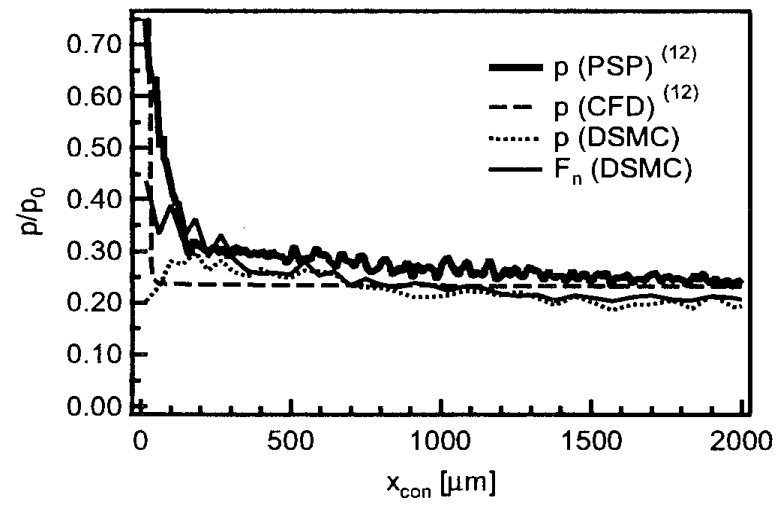

Fig. 1 Pressure profiles on single sharp-nose cone surface. $p$ (PSP) and $p(C F D)$ are experimental and numerical profiles from Ref. ${ }^{(12)} \cdot p(\mathrm{DSMC})$ and $F_{n}(\mathrm{DSMC})$ are gas and surface pressures obtained by DSMC method, respectively.

れる.この結果より，PSP で測定した場合も高クヌッ セン数流れにおいては前述の通りの圧力測定における 問題が現われ，少なくとも連続体領域において考えら れているような気体の静压を表している訳ではなく， 仮に圧力を表現しているとしても表面圧力であること が明らかとなった. なお, 前述の通り圧力孔による測 定でも同様に表面圧力が測定されることから，どちら の手法を用いても結果に差異は生じないことになる. この結果は, 膜内へ浸透する酸素分子量がヘンリーの 法則より気体圧力に比例しているという説明とは矛盾 するものである.

なお，この結果は思考実験として超高真空下で速さ と方向のそろった分子線が PSP に入射している状況を 考えても理解できる. 超高真空下であるために背圧は 非常に低く, 散乱した気体分子は入射してくる分子線 を妨げることはない，この場合，測定している量は気 体分子が表面に与える力積, 表面圧力 $F_{n}$ となること は容易に想像できる。一方, 状態方程式から求めた気 体圧力 $p$ では, 分子線の持つ大きな並進運動の方向が 変化することによる圧力への寄与が反映されないこと は明らかである。

\section{PSP が測定している物理量}

4.1 分子運動に基づく微視的な視点 PSP は励 起している発光分子が酸素分子によって消光される作 用を利用して圧力を測定しており, 消光量が多いとい うことは酸素分子数が多いことから圧力が高く, 消光 量が少ない場合は圧力が低いということになる. 消光 に寄与する酸素分子は, 流れ場から膜へと溶解し, 膜 内で拡散しながら消光させ，膜から離脱する，という 
プロセスを経ていると考えられる，よって，消光量は 膜内に存在する酸素分子数と比例しており, PSP が直 接的に表現しているものは膜内の酸素分子数であると 考えるのが自然である.

では, 膜内の酸素分子数はどのような物理量に支配 されているのだろうか. 膜へ溶解する分子数は，一般 にはへンリーの法則に従って気体圧力に比例すると考 えられている. しかし，低クヌッセン数流れでは気体 圧力と表面圧力は一致することから，全てのクヌッセ ン数領域に対して実際には前節の通り表面圧力に比例 していると考えることができる. PSP で用いられる高 分子膜は酸素透過性の非常に良いものが多く, 酸素分 子は比較的自由に膜に溶解することができると考えら れる. そのため, 分子運動から考えると, 膜へ溶解す る分子数が “運動量”ないし“力”によって決定される という解釈は適切とは言い難い．例えば，分子質量 $m$ と最確速さ $c_{m p}$ から代表的な運動量を求めると

$$
m c_{m p}=m \sqrt{\frac{2 k T}{m}}=\sqrt{2 m k T}
$$

となることから，温度が一定の場合は質量の大きい気 体ほど良く溶けることになってしまうが，現実にはそ うではない ${ }^{(8)}$. 溶解する分子数は膜内外の濃度が平衡 になるように決まっていると考える方が自然である. 次に, 膜内に溶存した酸素分子の運動を考えると, こ の運動は膜の温度，つまり表面温度 $T_{s}$ に依存する．励 起した発光分子を消光するのは三重項酸素であり, 消 光によって励起された酸素分子は一重項状態へと遷移 する．一重項状態の寿命は約 $40 \mu \mathrm{s}$ と報告されている (13). 酸素分子の膜内滞在時間にも依存するが, PSPで 用いられる高分子膜は酸素透過性が非常に高いため, 一つの酸素分子が膜内滞在中に消光を起こす回数は多 くないと考えられる. 最後に, 膜から離脱する酸素分 子数は溶解の逆反応としてとらえることができる.

以上から, 膜内の酸素分子数は膜内外の濃度平衡に よって決定されており, 膜外の濃度を決定づけるのは 膜へ到達する分子数であると考えられる．膜へ到達す る酸素分子数は気体分子運動論より分子数流束 $N$ と して次のように求めることができる.

$$
N=\frac{p}{\sqrt{2 \pi m k T_{g}}}
$$

PSP は圧力孔の実験值と良い一致を示すことから， もし分子数流束を測定しているならば，分子数流束と 表面圧力が比例関係にあることになる．この関係性に ついて検証した. 式 (9) と式 (4)を比較すると,

$$
F_{n}=\sqrt{2 \pi m k} \frac{\frac{T_{g}+T_{s}}{2}}{\sqrt{T_{g}}} N
$$

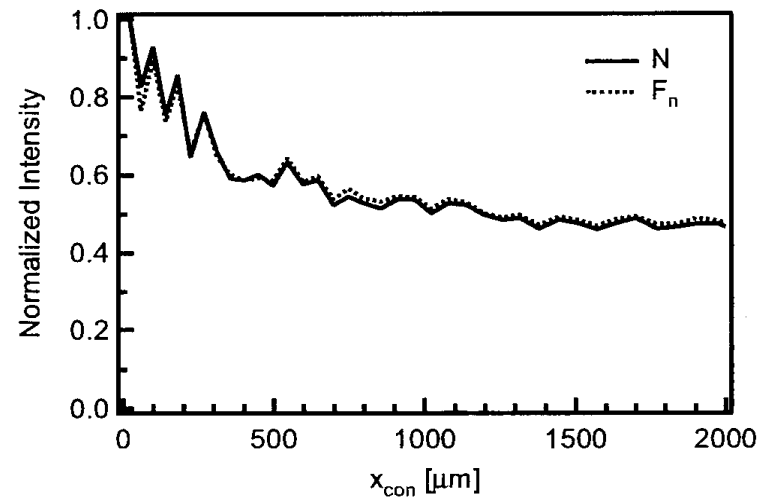

Fig. 2 Comparison between number tlux $N$ and surface pressure $F_{n}$ on surface obtained by DSMC method.

と書け, $T_{g} \simeq T_{s}$ であることを用いると

$$
F_{n} \propto \sqrt{T_{g}} N
$$

となることから，両者は厳密には比例関係にないこと が分かる. しかし, 実用上は PSPによって測定してい る領域内で温度が PSP の測定誤差を超えて大きく変 化していることは多くないと考えられる，また，PSP の温度依存性が問題視されていることから, 実験にお いては温度分布が極力生じない様に工夫することが多 いことも指摘できる. そのため, PSP が現在利用され ている流れ場では温度は大きく変化せず，両者は比較 的良い比例関係にあると考えられる．実際に前節の系 に扔いて DSMC 法によって求められた分子数流束 $N$ と表面圧力 $F_{n}$ を最大值を用いて規格化して比較する と, 図2 のようにほとんど差は見られない. よって, 仮にPSP が分子数流束 $N$ を測定していても, 実用上 は表面圧力が測定できていると考えても問題ないと考 えられる。

4.2 気体圧力測定の主張文献 ${ }^{(13)}$ は, “PSP は 圧力を測定しており, 密度の測定をしているわけでは ない”と主張している. その根拠として, 発光の圧力 感度と温度感度を理論的に求めた場合, 通常はどちら も負となるはずであるのに, 密度に比例すると仮定す ると, 状態方程式の関係より温度感度が正となること を挙げている. 今までの議論において, 気体圧力に依 存すると考えるよりも分子数流束を測定していると考 えた方が自然であることが明らかになった．流扎場の クヌッセン数によって PSP の測定原理が変わることは 考えづらいため, 連続体の仮定が成立する流れ場にお いても分子数流束を測定していると考えられるが，そ の仮定の下では温度感度の性質が説明できない可能性

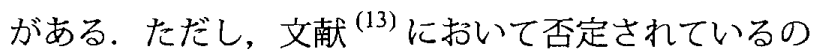
は気体流におけるバルクの数密度そのものを測定して 
いるという考えであり，本研究の指摘は PSP 表面へ 到達する分子数流束の測定であることに注意が必要で ある。

そこで, 文献 ${ }^{(13)}$ の議論に従って, 分子数流束を測定 していると考えた場合の温度感度を以下に考察する. 以下では，PSP が一般に使用されている連続体の仮定 が成立する低クヌッセン数流れ $(\mathrm{Kn}<0.01)$ を対象と している．そのため, 温度飛躍は生じず，表面近傍の 気体温度と表面温度は等しくなる $\left(T_{g}=T_{s}=T\right)$. ま ず Kinetic Model に従うと, 発光量 $e_{p}$ は, 三重項の量 子収率 $\Phi_{T}$, 比例定数 $a$, 三重項寿命時間 $\tau_{T}$ を用いて

$$
e_{p}=\Phi_{T} k_{E T} \tau_{T} a=\frac{\Phi_{T} k_{E T} a}{k_{E T}+k_{I T}+k_{Q T}}
$$

と表すことができる．下添え字はそれぞれ燐光 (ET), 項間交差 $(\mathrm{IT})$, 失活 $(\mathrm{QT})$ のプロセスを表し, $k$ は速度 定数である. $\Phi_{T}, a, k_{E T}$ は圧力にも温度にも依存せ ず， $k_{I T}$ は温度のみに次式のように依存する.

$$
k_{I T}=A_{I T} \exp \left(-\frac{\Delta E_{I T}}{R T}\right)
$$

酸素濃度の依存性を示すのは失活に関する項 $k_{Q T}$ のみ である. 失活のプロセスは酸素分子の膜への浸透性と 拡散性から決まり，二分子失活速度 $\kappa_{Q T}$ と膜内酸素濃 度 $\left[\mathrm{O}_{2}\right]$ の積によって表わされる. 二分子失活速度を決 定する浸透性と拡散性の積によって表現される透過係 数はつレニウス型の温度依存性を示し, 膜内酸素濃度 はへンリーの法則に従い酸素圧力 $p$ に比例することを 用いると，

$$
\begin{aligned}
k_{Q T} & =\kappa_{Q T}\left[\mathrm{O}_{2}\right] \\
& =A \exp \left(-\frac{\Delta E_{Q T}}{R T}\right) H p \\
& =A_{Q T} \exp \left(-\frac{\Delta E_{Q T}}{R T}\right) p
\end{aligned}
$$

と書ける. 温度感度 $S_{T}$ は次式で求められる.

$$
\left.S_{T} \equiv \frac{T}{e_{p}} \frac{\partial e_{p}}{\partial T}\right|_{p}
$$

仮に $e_{p} \propto \frac{1}{\rho}$ であれば $\left.\frac{\partial e_{p}}{\partial T}\right|_{p}$ は理想気体の状態方程式 $p / \rho=R T$ から温度依存性の符号が逆転して正になっ

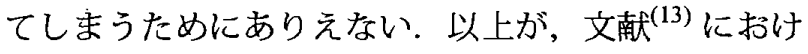
る結論である.

圧力ではなく分子数流束 $N$ を測定していると考え た場合にはどのようになるだろうか. 分子数流束 $N$ は 温度に対して $-\frac{1}{2}$ 乗の関係があるために, 上述の議論 に従うと, 温度感度の符号が問題となる可能性が否定
できない．分子数流束 $N$ が膜内酸素分子数に比例し， 失活速度を決定しているとした場合, 式(9)を用いて

$$
\begin{aligned}
k_{Q T} & =A_{Q T} \exp \left(-\frac{\Delta E_{Q T}}{R T}\right) N \\
& =A_{Q T}^{\prime} \exp \left(-\frac{\Delta E_{Q T}}{R T}\right) \frac{p}{\sqrt{T}}
\end{aligned}
$$

と書けることから, 温度感度は次式のようになる.

$$
\begin{aligned}
S_{T}= & -T \tau_{T} \frac{\partial}{\partial T}\left[A_{I T} \exp \left(-\frac{\Delta E_{I T}}{R T}\right)\right. \\
& \left.+A_{Q T}^{\prime} \exp \left(-\frac{\Delta E_{Q T}}{R T}\right) \frac{p}{\sqrt{T}}\right]\left.\right|_{p} \\
= & -\tau_{T}\left[k_{I T} \frac{\Delta E_{I T}}{R T}+k_{Q T}\left(\frac{\Delta E_{Q T}}{R T}-\frac{1}{2}\right)\right]
\end{aligned}
$$

となる. 発光分子と膜分子が PtTFPP/FIB の組み合わせ の場合, 文献 ${ }^{(13)}$ に示された值を代入すると $S_{T}=-0.26$ となるため, 正負の傾向を再現できることが分かる. $\Delta E_{Q T} / R T$ が小さく $S_{T}$ の正負が逆転する可能性のある RudpCl/Ethanol の場合でも $S_{T}=-0.14$ となり, 問題 はない. よって, 少なくとも分子数流束に発光が依存 していたとしても, 否定できるものではないことが明 らかである. な扔, 絶対値としては圧力と考えた場合 と同様に，実験值より小さくなってしまう，しかし， 温度依存性がほとんど知られていないために考慮でき ていない項があり，実験值とのずれはその影響による と考えられる.

\section{おわりに}

高クヌッセン数領域に感圧塗料を適用した場合に起 こる問題について, 分子運動論的な見方から考察を行 なった.

一般に, 表面近傍ではヘンリーの法則によって膜内 に浸透する酸素分子数が決まると考えられている.し かし, 高クヌッセン数流れにおいては圧力孔によって 測定した場合, 気体の圧力ではなく気体分子の力積に よる表面圧力とよい一致をすることが知られている. そこで, 高クヌッセン数流れに感圧塗料を適用した場 合に対する考察より，感圧塗料の測定原理に対する新 しい提案を行なった.

1. マイクロ円錐体の実験結果と直接シミュレーショ ンモンテカルロ法の数值解析結果から, クヌッセ ン数の大きくなる先端近傍で感圧塗料の測定結果 は気体の圧力ではなく表面圧力と同じ傾向を示す ことが明らかとなった。

2. 分子運動に基づく考察より, 感圧塗料の測定して いる物理量は分子数流束である可能性が高いこと を示した. 
3. 感圧塗料の測定している物理量が分子数流束に依 存している場合, 温度が変化すると気体圧力とも 表面圧力とも比例しなくなるものの, 実用上は感 圧塗料の温度依存性を避けるために温度分布の変 化量を小さくする工夫が施されていることが多く, 問題にならないと考えられる.

4. 温度感度の解析から感圧塗料は圧力に従っており 密度を測定しているわけではない, という主張も あるが, 微視的な考察から導かれるように分子数 流束に従っていると解䣋しても傾向自体に関して は矛盾がないことを示した.

\section{謝辞}

本研究の一部は科学研究費補助金の助成を受けて実 施した. また, 東北大学大学院工学研究科航空宇宙工 学専攻 浅井圭介教授ならびに永井大樹助教には実験 及び CFD 解析結果を提供して頂いた。ここに記して 謝意を表す。

\section{文献}

(1) Liu,T. and Sullivan,J.P. Pressure and temperature sensitive paints, Berlin: Springer, (2005).

(2) Niimi,T. et al., Application of pressure-sensitive paints to low pressure range, Journal of Thermophysics and Heat Transfer, 19 (2005), pp.9-16.

(3) Mori,H. et al., Application of PSP to low density gas flows, Journal of Visualization, 7 (2004), pp.55-62.

(4) Mori,H. et al., Molecular number flux detection using oxygen sensitive luminophore, Physics of Fluids, 17 (2005), pp.100610-1-100610-6.
(5) Mori,H. et al., Pressure sensitive paint suitable to high Knudsen number regime, Measurement Science and Technology, 17 (2006), pp.1242-1246.

(6) Matsuda,Y. et al., Development of Pressure Sensitive Molecular Film Suitable to Pressure Measurement of High Knudsen Number Flows, Transactions of the Japan Society of Mechanical Engineers, Series B, 72-718 (2006), pp.1475-1482.

(7) Yamaguchi,H. et al., Discussion on Mechanism of Pressure-Sensitive Paints, Transactions of the Japan Society of Mechanical Engineers, Series B, 73-725 (2007), pp.112-117.

(8) The Society for Chemical Engineers, Japan ed., Handbook of Chemical Engineering(in Japanese), Maruzen (1999), pp.80-81.

(9) Lengrand,J.C. et al., Rarefied Hypersonic Flow over a Sharp Flat Plate: Numerical and Experimental Results, 18th International Symposium on Rarefied Gas Dynamics, 160 (1992), pp.276-284.

(10) Schaaf,S.A. and Hornig,D.F., Flow of Rarefied Gases, High Speed Aerodynamics and Jet Propulsion, III Sec.H, Princeton, (1958), p.687.

(11) Bird,G.A., Molecular Gas Dynamics and the Direct Simulation of Gas Flows, New York: Oxford University Press, (1994).

(12) Osafune,T. et al., Application of Molecular Sensors to Micro Objects in Supersonic Flow, (2004), AIAA Paper 2004-1048.

(1.3) Bell,J.H. et al., Surface Pressure Measurements Using Luminescent Coatings, Annual Review of Fluid Mechanics, 33 (2001), pp.155-206. 